\title{
أثر استيعاب القواعد النحوية والمفردات على قدرة الترجمة لدى طلبة الجامعة الإسلامية الحكومية قدس
}

\author{
Azwar Annas
}

IAIN Kudus, Kudus, Indonesia

Email: azwarannas273@gmail.com

\begin{abstract}
This study sought to determine the influence of grammar and vocabularies mastery on the students ability of translate in the Kudus Islamic University. The approach articles used in this study is a quantitative approach because researchers wanted to test the hypothesis that shaped assosiative hypothesis (is the hypothesis that asks a relationship between two or more variables). This approach is said to be a quantitative approach because the existing data in the form of numbers and statistics used in analyzing it. Meanwhile, the method used is research Correlation, because the correlation study researchers wanted to uncover the relationship of variations in the correlation coefficient. The results of this research are: 1) the effect of gramatikan mastery to capability students of translate in the Kudus Islamic University as 0.4925 rhitung score greater than 0.317 rtabel. This shows a significant correlation while the coefficient of determination between $X_{1}$ and $Y$ of $24.25303 \%$. 2) the effect of vocabulary mastery to capability students of translate in the Kudus Islamic University as a score of 0.605 rhitung greater than 0.317 rtabel. This shows a significant relationship coefficient of determination between $X 2$ and $Y$ amounted to $36.62499 \%$, 3) The calculation Ry.X1X2 0.589, ryx1 0.492 and 0.605 ryx2 greater than 0.317 rtabel. This shows that there is a relationship multi positive correlation between mastery of vocabulary and grammatical to capability students of translate in the Kudus Islamic University and acceptance of the hypothesis.
\end{abstract}

Keywords: Grammar, Vocabulary, Translate.

$$
\begin{aligned}
& \text { والعاطفية التي ستدرج في لغة } \\
& \text { الهدف (BT) يجب أن يكون } \\
& \text { مفهومها بشكل صحيح. الوعي } \\
& \text { الخاص بنفس الأصل ينبغي أن } \\
& \text { يقدم للمطلوب، بكيث المسائل } \\
& \text { المتعلقة بإعداد الكلمات والعبارات } \\
& \text { والتعبيرات المحرمات، والتوقعات } \\
& \text { المحلية وغيرها يمكن أن يحسبوا بدقة } \\
& \text { لأن الترجمة ليست ججرد نقل أو أو }
\end{aligned}
$$

$$
\begin{aligned}
& \text { كثير من الناس } \\
& \text { يقولون أن لا يوجد عمل أكثر } \\
& \text { صعوبة من نشاط الترجمة. لابد } \\
& \text { على المترجمين أن يملكوا استيعاب } \\
& \text { لغة المصدر (BS) صحيحا لكنهم } \\
& \text { يجب أيضا أن يكونوا لهم فهم دقيق } \\
& \text { يتضن في نصوصها من مجالات } \\
& \text { المعرفة. وهذا هو، كل من ل كن } \\
& \text { الدلالات الاجتماعية والثقافية }
\end{aligned}
$$


قواعد اللغة، وإنما في ضعف السليقة اللغوية بين الناس على اختلاف مستواياتم حتى ألفوا الخطأ إلى الدراجة التي أصبحوا ينفرون فيها من الصحيح والعلاج، وفي رأيه أيضا، ليس بزيادة ساعات

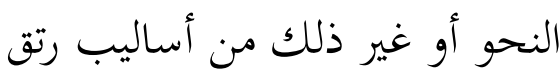
الثوب اللغوي المهلهل وإنما يتطلب الأمر في رأيه أيضا إعادة النظر في جو المدرسة كله، حتى قيئ فرصة

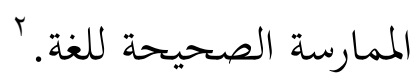

ومن أمر مهم فئه في

قدرة الترجمة هو استيعاب القواعد النحوية والمفردات. هذه الكفاءة

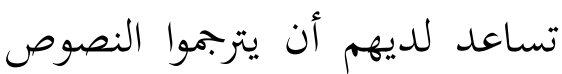
موفقا. وعدد المفردات التي لئي يستعبون بها بحسب ما يريدون من

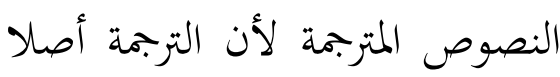
هي نقل النص الدلالي من لغة المصدر التي تبنى من المفردات،

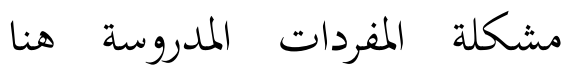

\footnotetext{
' رشدى أحمد طعيمة، المرجع في تعليم اللغة

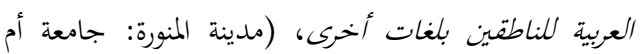
القرى، 1911)، ص. • •
}

تغيير لغة المصدر إلى الهدف، بل

$$
\text { أكثر من ذلك. }
$$

وبصورة عامة،

نستطيع أن نحدد الترجمة بأهما شكل معقد من أشكال النشاط الإنساني، في تحويل المعلومات اللغوية، الذي يمكن أن يتخذ شكل

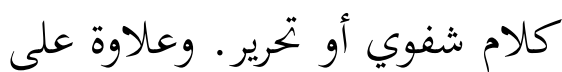

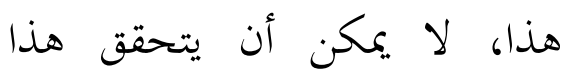

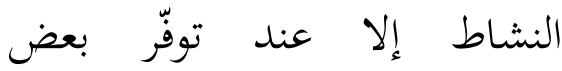
الشروط، مثل استيعاب اللغتين، المنقولة والمنقول إليها، والقدرة على

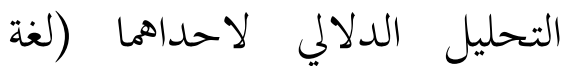
الأصل)، وعلى التركيب الدلالي بوسائل اللغة الأخرى (لغة الترجمة)، وامتلاك خبرة الانتقال من التحليل الدلالي إلى التركيب الدلالي، وتوفر

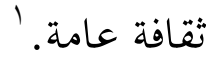
رأى رشدى أحمد طعيمة أن المشكلة الأساسية في راكي الاستخدام اللغوية ليست في عدم حفظ مبادئ النحو أو استظهار

$$
\begin{aligned}
& \text { ' أسعد مظقّر الدين حكيه، علم الترجة النظري، } \\
& \text { (دمشق: طلاس، 1919)، ص. } 09 \text { ( } 199
\end{aligned}
$$


في جامعة الإسلامية الحكومية قدس. وهذه القسم إحدى مراكز نشر العلوم الاسلامية. وكان الطلاب في هذه كلية كثير منهم متخرجين من المعهد الإسالامية و المدرسة الإسلامية، و كانوا يتعلموا اللغة العربية منذ ثلاث سنوات أو

ست سنوات أو تسع سنوات، ومن البياناب التى وجدها الباحث أن الطالاب من قسم اللغة العربية قادرا على استيعاب القواعد النحوية ولديهم كفاءة المفردات.

نظرا إلى الواقع أن

كثيرا من طلاب المرحلة السادسة من قسم اللغة العربية بجامعة الإسلامية الحلكومية قدس يشعرون صعوبة بقدرة على الترجمة مع أفم يتعلمون دروس اللغة العربية ويتعلمون علوم الدينية وعلوم القرآن ويستحقون أن يتحدثوا باللغة العربية احيانا.

بناء على ما سبق ذكره، أن القواعد النحوية والمفردات
يشمل على المفردات في لغة المصدر أو النصوص المترجمة.

ومن المعروف أن

المفردات عنصر مهم من عناصر اللغة المهمة. هذا البيان يدل على أن المفردات والترجمة شيء مترابط بعضها ببعض. فلا عجب إذا تعلمها الطلاب في المدارس والمعاهد الاسلامية في بلاد إندونيسيا على

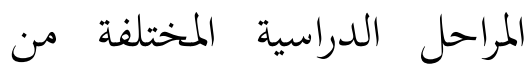
الابتدائية إلى الجامعة الإسلامية . إضافة إلى ذلك فالمفردات هي أدوات للحصول على معاني النصوص. وبالمفردات يستطيع المتكلم أن يفكر ثم يترجم فكرة إلى كلمات تحمل مايريد. حينما يتعلم الطلاب اللغات الأجنبية كانت المفردات لها دورة هامة لأهما نظام أساسي من النظام اللغوي كالنظام الصوتي و النظام الصرفي و النظام النحوي والنظام الدلالي. وإن قسم "اللغة العربية" من الكلية التربية التي تقوم 
r. إلى أي مدى أثر استيعاب

المفردات في قدرة الترجمة لدى

الطلبة في الجامعة الإسلامية

الحكومية قدس؟

r. إلى أي مدى أثر استيعاب

القواعد النحوية والمفردات في

قدرة الترجمة لدى الطلبة في

الجامعة الإسلامية الحكومية

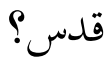

مفهوم القواعد النحوية وأهداف

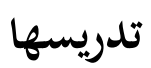

القواعد هي وسيلة حفظ

الكلام وصحة النطق والكتابة،

وهي ليست غاية مقصودة لذاتا

بل هي وسيلة من الوسائل التي

تعين المتعلمين على التحدث

والكتابة بلغة صحيحة.

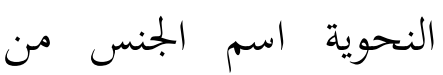

النحو. وقد عرّف النحو قديما بأنه

العلم الذي يعرف به ضبط أواخر

r طه على حسين الديليمي، وسعاد عبد الكريم.

عباس الوائلي، اللغة العربية مناهجها وطرائق تدريسيها،

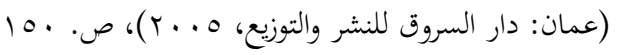

عنصور من قدرة الترجة ويشعر

الباحث بحاجة إلى القيام بالبحث

عن آثر استيعاب القواعد النحوية

والمفردات في قدرة الترجمة. لذا يدفع

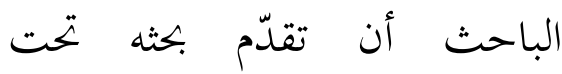

الموضوع " أثر استيعاب القواعد

النحوية والمفردات على قدرة

الترجمة "، كما اختر الباحث عن

هذا الموضوع لبحثه في البحث

يخصص الباحث الطلاب للمرحلة

السادسة في قسم اللغة العربية

بجامعة الحكومية الأسلامية قدس،

حيث هذا القسم يجعل المترجمين من

المادة المقررة فيه ومن المعلوم أفّم

يفهمون اللغة العربية ويماهرونها.

اعتمادا على الخلفية

السابقة حدد الباحث مشكلات

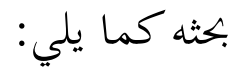

ا. إلى أي مدى أثر استيعاب

القواعد النحوية في قدرة الترجمة

لدى الطلبة في الجامعة

الإسلامية الحكومية قدس؟ 
الكلام وفهم ما يقرأ أو يسمع أو يكتب أو يتحدث به فهما صحيحا، وتستقر معه المفاهيم في ذهن المؤدي أو المتلقي وتتضح به المعاني والأفكار وضوحا لا غموض

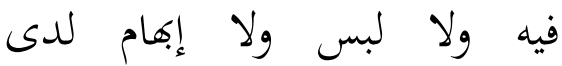
المتحدث أو المستمع أو القارئ أو لوإ الكاتب فلا بد عليهم أن يستعيبوا القواعد النحوية.

القواعد النحوية العربية تنقسم إلى ثلاثة أنواع، هي التركيب (kalimat) والجملة) والأسلوب (style). لاتساع الدراسة فيها يركز الباحث بحثه عن التركيب.

\section{التركيب (frase)}

المركب في اللُّة: وضْع شيء على شيءً جاء في "اللسان" و"القاموس": "رََّّب الشيءَّ: وَضَع

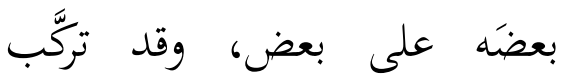

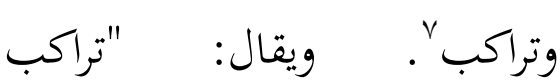
السَّحاب وتراكم: صار بعضُه فوق

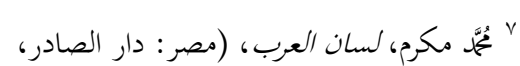

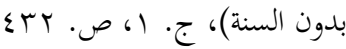

الكلمات ومعرفة حالتها إعرابا وبناء وتركيب الجملة. ؛ أما المفهوم الحديث لعلم النحو فهو علم البحث في التراكيب وما يرتبط بها من خواص كما أنه يتناول العلاقات بين الكلمات في الجملة وبين الجمل في العبارة. ْالنحو قواعد يعرف بها وظيفة كل كلمة داخل الجملة، وضبط أواخر

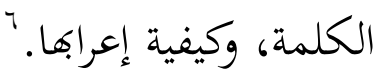
ولذلك، أن القواعد النحوية وسيلة لتقويم الألسنة وعصمتها من اللحن والخطأ. فهي التعين على دقة التعبير وسلامة الأداء لتستَخدم اللغة استخداما صحيحا. وخلاصة القول إذا كان الطلاب يريدون أن يدركوا مقاصد

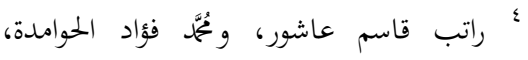
أساليب تلدربس اللغة العربية، (عمان: دار الميسرة،

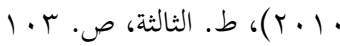

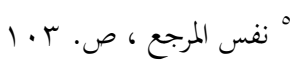

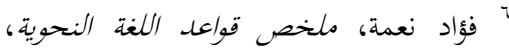
(بيروت: دار الثقافة الإسلامية، بدون السنة)، ط. 19 1، IV ص 
وعلاوة ذلك، يكون المركب

في أعلى الكلمة وأدنى الجملة ولم يصر جملة ولا كلاما (klausa) ولو يكون من الكلمات.

عند الغلاييني أن المركب ستة أنواع: إسناديّ وإضافيّ وبيانيّ

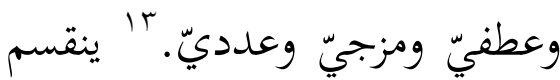

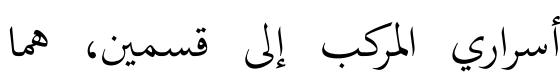
المركب الفعلي والمركب غير العفلي. المركب الفعلي (Frase Verba) هو يتكون من الفعل وله التوزيع

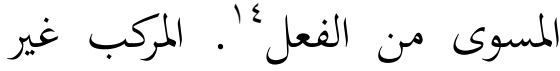
الفعلي (Frase Non Verba) هو تبدأ بالاسم بخلاف الفعلي الذي يبدأ بالفعل. المركب غير الفعلي ينقسم إلى خمسة منها المركب الاسمي (Frase Nomina) والمركب المب الوصفي (Frase Sifat) والمركب الظرين (Frase Adverbia) والمركب العددي (Frase Numeral) ومركب شبه الجملة (Frase Preposisi). "ا غلاييني، المرجع السابق، جامع الدروس

${ }^{14}$ Imam Asrori, Sintaksis Bahasa Arab, (Malang: Misykat), 2004, hlm. 46

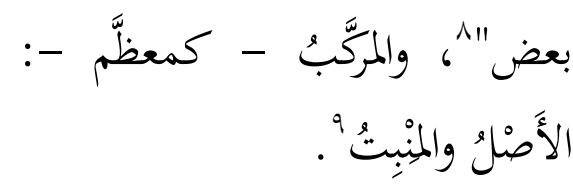

المركب عند النحويين: ما

تكون من كلمتين أو أكثر. '' هو العحوين'

قول مؤلف من كلمتين أو أكثر

لفائدة، سواء أكان الفائدة تامة مثل، "النجاح في الصدق"، أم أم أماء

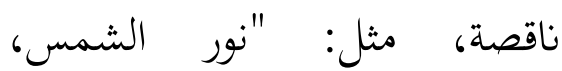

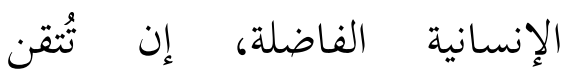

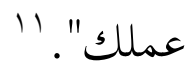

يقصد به بمموعة من العناصر ترتبط ببعضها وتصلح لأن تشغل وظيفة واحدة في الجملة، أي أثها تسوي نغويا كلمة مفردة، ويستبدل بمجموع عناصرها اسما أو أو فعلا.

$$
\begin{aligned}
& \text { ^ أبو نصر إسماعيل بن حماد الجوهري الفارابي، }
\end{aligned}
$$

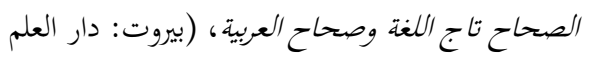

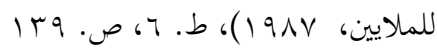

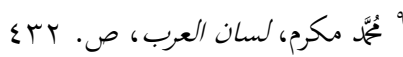

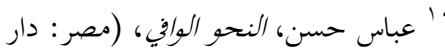

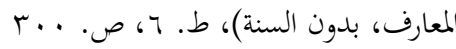

$$
\begin{aligned}
& \text { '" مصطفى غلاييني، جامع الدروس العربية، }
\end{aligned}
$$

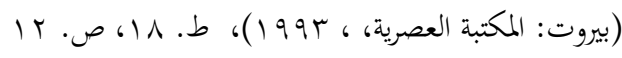

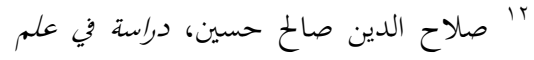

$$
\begin{aligned}
& \text { اللغة الوصفي والتاريخي والمقارن، (رياض: دار العلوم للطباعة } \\
& \text { والنشر، 1911)، ص. ع ع 170-170 }
\end{aligned}
$$


جalimat majuk (الجملة المعقدة

(bertingkat

هي جملة أحد عناصرها

independent ) الأصلية الرئيشية

(clause/induk jumlah

(dependent clause/anak jumlah)

جملة فعلية أواسمية أومصدر مؤول.

$$
\text { الأسلوب (style) }
$$

أ) أسلوب القسم (pola sumpah)،

الغرض منه تأكيد حدوث

$$
\text { المقسم عليه. }
$$

pola ( أسلوب المدح والذم

هو (pujian dan celaan

أسلوب يقصد به ملح

خصوص بالمدح أو ـ ذم

خصوص بالذم، وله أفعال

جامدة خاصة، ملازمة

للمضى6 هي: نعَّ، بئس؛

حبّذا، لاحبّذا.

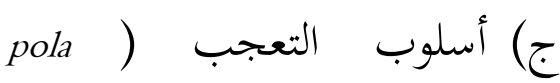

(kekaguman )، هو أسلوب يدل بل

"1 سليمان فياض، النحو العصري: دليل مبسط

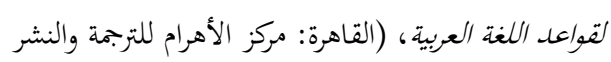

ror.
ابلمملة (kalimat)

إعتمادا على المشكلة

وحلها، تنقسم الجملة العربية إلى ثاثلة أنواع، هما: الجملة البسيطة، والجملة المركبة، والجملة المعقدة.

kalimat ) ألجملة البسيطة (tunggal

المقصود بها في هذا السياق

يعنى الجملة لها المسند والمسند إليه حسب. المسند إليه هو المبتدأ الذى له خبر والفاعل ونوابه وأسماء النواسخ. أما المسند هو الخبر والفعل. وفقا باللغة الإندونيسية أن المسند إليه يسمى Subjek ، والمسند يسمى Predikat.

kalimat ) الجملة المركبة (majmuk setara

هي جملة كانت تشمل في ثناياها على أكثر من جملة أو أكثر من فكرة. 10 غالبا، هذه تؤشر بكون حرف العطف (الواو، الفاء، بل، لكن، أم، أو، ثم) بين الجمل.

10 10 مُجْ حسين مغالسة، النحو الشافي، (بيروت: مؤسسة

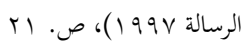


وفكره بكلمان ما يريد. 19 وهي إحدى العناصر اللغوية التى تنبغي

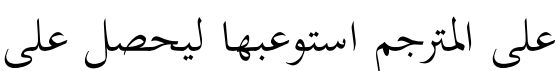
الكفاءة اللغوية المرغوبة. ولعل أكثر المهارات والقدرات توظيفا للمفردات واعتمادا عليها هي الترجمة، حيث يفتقد المترجم الموقف الحي الذي تستعمل فيه اللغة والذي يكون في غالب الأمر مصحوبا بقرائن تساعد على فهم اللغة وتسد ما قد ينشأ من خلل في توصيل معانى المفردات ألى أذهان قارئ الترجمة. الأمر في الترجمة إذن يعتمد على قدرة المترجم على فهم المفردات التي يتكون منها النص الأصلي. وإدراك العلاقة بين بعضها وبعض.

\section{أنواع المفردات أو كلمات}

أ) كلمات المتوى ( content ) ويقصد ) vocabulary مجموع المفردات الأساسية التي

" معمود كامل الناقة، تعليم اللغة العربية بلغات

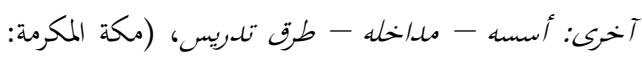

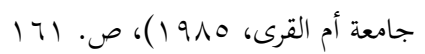

على استعظام صفة في شيئ ما، ذاتا كان هذا الشيئ أو

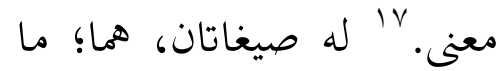
أفعَل، وأفعِل بـ. د) أسلوب الاغراء والتحذير ،(pola anjuran dan larangan) أسلوب الإغراء هو أسلوب خاصة على أن يفعل أمرا محمودا. والتحدير هو أسلوب خاصة إلى أمر مذموم ينبغي

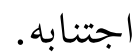

\section{مفهوم استيعاب المفردات}

مفردات جمع من مفرادة:

كلمات "مفردات لغوية - يحتوي هذا الكتاب على مفردات لغوية صعبة". مفردات اللغة هي جميع

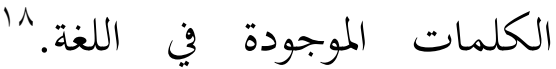
والمفردات هي أدوات حملت المعنى كما أها في وقت آخر كوسيلة للتفكير. لأن المتكلم يستطيع أن وفت احتر يفكر ثم يعبر ما خطر في باله

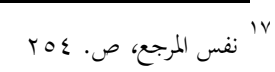

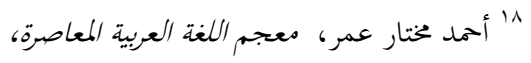

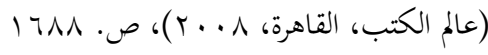


إن معنى الكلمة ينقسم إلى

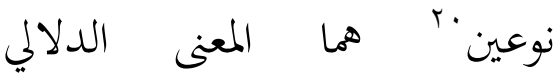

(denotatif)

أما المعنى الدلالي فهو المعنى يتحقق

في القاموس ويبضمن على المعنى

الحقيقي والقياسي. على سبيل المثل

كانت كلمة "الأم" لها معنى حقيقي ليعي سيعي

هو "من يولد الولد". و "الأم" في

"أم الكتاب" لها من معنى قياسي.

ويتضمن أيضا على المعنى الأصلى

والاصطلاحي. في كلمة "الهاتف"

لما معنى الأصلى هو "من يخاف

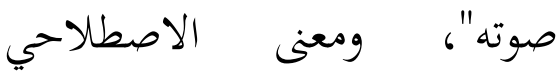

هو"تليفون". أما المعنى الإضافن

فهو ما يضيف به المعنى من الظلال

والانطباع كحصول الخبرة كمن

يستخد اللغة. كمثال "الأم" لها لهن

معنى إضافي "من ذات العاطفة

$$
\text { والحارسة". }
$$

وتنقسم المفردات إلى

القسمين من ناحية أهميتها هما

المفردات المعجمية والوظيفية. الأولى

${ }^{20}$ Ahmad Fuad Effendy, Metodologi Pengajaran Bahasa Arab, (Malang: Misyka, 2012), cet. 5, hlm. 127
تشكل صلب الرسالة مثل

الأسماء والأفعال.

function ( بلمات وظفية

) ويقصد بها مجموع

المفردات التي تربط المفردات

والجمل والتي يستعان بها على

إتمام الرسالة مثل حروف الجر بل

والعطف وأدوات الإستفهام

$$
\text { وأدوات الربط بشكل عام. }
$$

ج) كلمات عنقودية ( cluster

) ويقصد بها مجموع

المفردات التي لا تنقل معنى

معينا وهي مستقلة بذاتها وإنما

تحتاج إلى كلمات أخرى

مساعدة تنقل من خلالها إلى

المستقبل معنى خاصا مثل

(رغب) فهذه الكلمة تكون

بمعنى أجب في قولنا: رغب في

وتكون بمعنى انصرف في قولنا: 
نص المصدر لا يمكن أن يتحقق إلى إلا باستيعاب المفردات. وحل مشكلها من خلال الاستنفاد. على ذلك، فإن هذه القضية تواجه دائما للمترجم على كل ورقة من الأوراق المترجمة. المترجم قد يواجه الإحباط عندما لا تكون عليه قدرة لحل هذه

$$
\text { المشكلة. }
$$

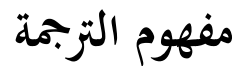

الترجمة مصدر ترجم، ترجم

القرارَ إلى عمل: نفذه أو نقله إلى

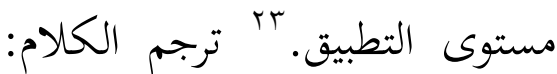
فسره بلسان آخر.

الترجمة اصطلاحا عند

الدكتور أسعد مظفر الدين حكيم أنها عملية تحويل إنتاج كلامي في إحدى اللغات، إلى إنتاج كلامي في لغة أخرى، مع المحافظة على إلى
هي المفردات التي لها معان في القاموس مثل "بيت، قلم، سيارة". أما الثانية هي المفردات التي تتضمن الفائدة، مثل "حرف الجار، أسماء

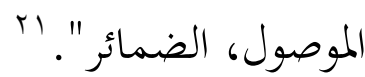
موقف المفردات في الترجمة

المفردات من أمر مهم فيها. وهي أساس لتركيب النصوص المترجمة والنصوص المحصولة منها، لأن الترجمة أصلا هي نقل النص الدلالي من لغة المصدر التي تبنى من المفردات، مشكلة المفردات المدروسة هنا يشمل على المفردات في لغة المصدر أو النصوص المترجمة. rr

الخطوة الأولى في عملية

التربمة هي تعميق نص المصدر. وفي هذه الخطوة برزت مشكلة المفردات كالقضية المهمة. تعميق

\begin{tabular}{|c|c|c|}
\hline \multicolumn{3}{|l|}{${ }^{21} \mathrm{Ibid}$, hlm. 127} \\
\hline $\begin{array}{ll}22 & \text { Ibnu } \\
\text { emah: } & \text { Metode }\end{array}$ & $\begin{array}{l}\text { Burdah, } \\
\text { dan }\end{array}$ & $\begin{array}{r}\text { Menjadi } \\
\text { Wawasan }\end{array}$ \\
\hline Teks & Bahasa & Arab, \\
\hline
\end{tabular}




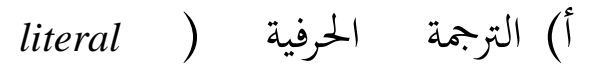

(translation

هي تسعى حفاظا على

شكل (أسلوب) ومعنى نص لغة

المصدر دون اهتمام أكانت هذا

الشكل أو الأسلوب غالبا في اللغة

المدف، و أيمكن للقارئ أن يفهم

هذه الترجمة أم لا.

لذلك، هذه الترجمة تحول

الألفاظ أو المفرادات من لغة (لم)

إلى أخرى (له). وتفضل تكافؤ

المفردة والتعبيرة في (له) اللتان

توافقان في (لم). بالطبع لا يمكننا

دائما استخدام الترجمة الحرفية، فإن

استخدامها في كثير من الأحيان لا

يعطي أي معنى للجملة المترجة.

faithful ) الأمنية

(translation

تميزت هذه الترجة بوجود

التحالف على المؤلفات الأصلية

والنصوص بلغة المصدر. تعتبر

${ }^{26}$ Zuchridin Suryawinata \& Sugeng

Heriyanto,Translation: Bahasa Teori \& Penuntun Praktis Menerjemahkan,

(Yogyakarta: Kanisius, 2003), hlm. 48
جانب المضمون الثابت، أي على<smiles>[AlH2][Hg][AlH2]</smiles>

اعتمادا على التعريفات

السابقة، استخلص الباحث بأن

الترجمة محاولة النقل من لغة المصدر

(يقصد في هذا السياق اللغة

الغربية) إلى ما يعادلها من لغة

المدف (يقصد في هذا السياق اللغة

الإندونيسيا). ولذلك، قدرة الترجمة

هي قدرة على محاولة النقل من لغة

المصدر (يقصد في هذا السياق

اللغة العربية) إلى ما يقابلها من لغة

المدف (يقصد في هذا السياق اللغة

الإندونيسية).

طرائق الترجمة

اعتمادا على عملية الترجمة،

تفصل على النوعين، هما من جانب

لغة المنقول وون جانب لغة

المصدر. تنقسم الترجمة ثلاث

أنواع من جانب لغة المنقول؛ 
يرى ل. س. بارخوداروف

أن الترجمة التصرفية هي الترجمة لرحتر المنفذة في مستوى أعلى من المستوى الازم لنقل جانب المضمون الثابت، مع مراعة قوانين لغة الترجمة. إن التكافؤ في الترجمة الحرة يتحقق، كقاعدة عامة، في مستوى وصف الموقف، وفي أحسن الأحوال، في مستوى الأعلام. إن وتئ احسن المعلومات، المنقولة في مستوى القول والرموز اللغوية، تبقى عادة غير مصورة. تؤدي مثل هذه الترجمة -لدرجة كبيرة- إلى الأسهاب، أي لـ إلى وصف الموقف المناسب بأية وسائل، بصرف النظر عن طريقة وصف هذا الموقف في النص الأصلى. تقيم الترجمة الحرة التطابقَ مع النص الأصلي، في لغة الترجمة، بصورة بعيدة عن مكونات الأصل

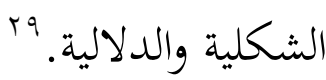

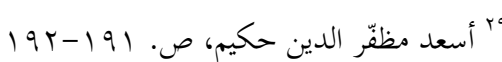

الأسلوب واختيار الكلمات لأغا

من سمات المؤلف. ومع ذلك، دراجة اصطفاقة هذه الترجمة أدنى من الترجة الحرفية، لأن بنية (لم) قليل اهتمامه. ج) الترجمة الدلالية ( semantic (translation

قال نيومارك، أن الترجمة الدلالية تستخذم لتراجم النصوص الموثوقة (otoritatif) أو المعبرة (ekspresif) المتويات والأسلوب؛ و والفكرات والمفردات؛ والتراكيب كلها مهتم، كما كان في النصوص الأدابية. ^r إذا، هذه الترجمة نقل معنى النص نقلاً دقيقا مع مراعاة القيمة الجمالية للنص الأصلي ، بحيث

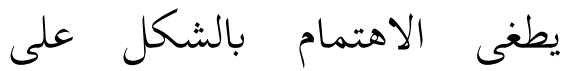
المضمون. وتشمل على ثلاثة أنواع من لغة المصدر؛

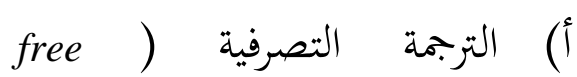
(translation 
لابد على العناصر الثقافة من (لم) تبدل إلى الثقافة من (له).

\section{عملية التزجمة - م}

أ) تحليل رسالة النصوص المنقولة الخطوة الأولى من تحليل

رسالة النصوص من (لم) هي أن

يفهم المترجم ابتحاه ومحتوى الكتب

شاملا بأن يعتمد بطرائق، منها

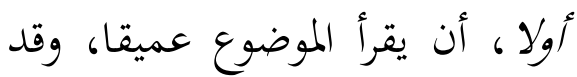

يكون الموضوع يتصله إلى صورة

إجمالية من الكتاب. لاسيما،

موضوع من الكتب العربية لما صيفة

مباشرة (direct) والعكس بهن

الكتب الإندوبيسية غالبا. "r ثانيا،

أن يحدد فهرس الكتاب المنقول، قد

تعكس الأبواب فيه نتائج أو موافق

المؤلف عن الأحوال المبحوثة. ثالثا،

أن يقرأ الخاتمة (epilog) لأن فيها

ما أشد فعالا ليفهم ابتاهات

الكتاب، يكتب المؤلف النطقات

$$
\text { فيها بالكلمات الموجزة. }
$$

${ }^{32}$ Ibid, hlm. 15

${ }^{33}$ Ibnu Burdah, Menjadi Penerjemah:

Metode dan Wawasan Menerjemah Teks Bahasa Arab, (Yogyakarta: Tiara Wacana, 2004.), hlm. 29
ب) الترجمة الاصطلاحية أو الحيوية

idiomatic or dynamic )

\section{(translation}

الترجمة الاصطلاحية هي

الترجمة التي تسعى أن تعبّر عن

مقصد الكاتب في ألفاظ أو جمال

لغة المدف المرونة. هذه الترجمة لا لا لاع

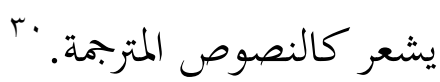

أما الترجمة الحيوية عند نيدا لمران

وتابر هي الترجمة تشمل العناصر

الخمسة، منها: إعادة الانتاج من

الرسالة، والمعادلة (ecuifalent)؛

والتكافؤ العلمية، و التكافؤ المقربة،

وأن تفضل المعنى.'

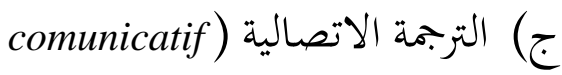

\section{(translation}

الترجمة الاتصالية تسعى أن

تجعل أثرا لقارئ لغة الترجمة مثل

قارئ اللغة المنقولة. لذلك، لايكون

من لغة الترجمة إلا أن تفهم وترشق.

${ }^{30}$ Abdul Munip, Strategi dan Kiat Menerjamah Teks Bahasa Arab kedalam Bahasa Indonesia, (Yogyakarta: Teras, 2009), hlm. 14

${ }^{31}$ Ibid, hlm. 14 
الرسالة أو الأجواء من نصوص

ب) وضع رسالة النصوص من

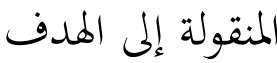

بعد انتهاء العملية التحليلية - الخطوة التي تتضمن على جانبي القواعد ودلالة النص المترجمة-

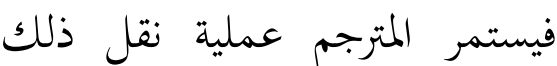
التحليل في عقله من (لم) إلى (له).

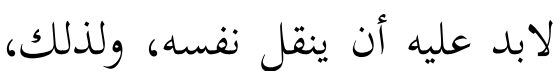

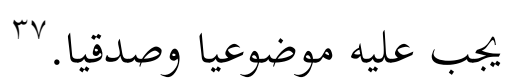
وفيما يتعلق بأجراءات الترجمة يتعين على المترجم أن يقوم بعملية أختيار متواصلة في كل مقطع كتابي أو جملة أو وحدة إندارة ترجمية بمدف تحديد أهميتها لنقل الأفكار في النص الذي تتم ترجمته.

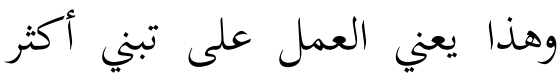
الأستراتيجيات والأساليب مناسبة تين العنر التي تتناغم مع متطلبات النص وليس تبني أسلوب ما والدأب على لئى أستخدامه حتى النهاية. ويتعين

${ }^{37}$ Abdul Munip, Strategi dan Kiat Menerjamah Teks Bahasa Arab, hlm. 19
الخطوة الثانية هي أن

يكسب فهما عن موقف الكتاب.

طبعا، الكتاب أو المقالة يكونان في

الموقف المعين. على سبيل المثال، المقالة تكتب كالنقيد أو تقوية

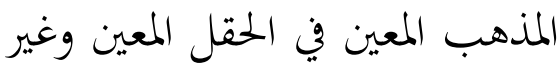
ذلك. الخطوة الثالثة هي أن يقرأ

الكتاب قراءة سريعة (scimming)

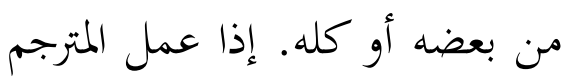
الخطوتين الأوليين بدقة ليسلك إلى

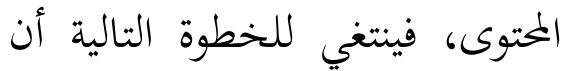
ينفذها برفق لا يحتج تفكيرا خاطرا

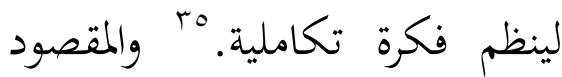
من هذه العملية أن يشعر أجواء على المؤلف. الخطوة الرابعة هي أن يقرأ قراءة جيدة من الإبتداء إلى الإنتهاء وهو يطلب المعانى الصعوبة من القموس. ولا يعجل أن يترجم النصوص المقروءة مباشرة. بَ" وينبغي له أن يتلوها تلاوتين فأكثر ليلتقي
${ }^{34}$ Ibid, hlm. 30
${ }^{35}$ Ibid, hlm. 31
${ }^{36}$ Ibid, hlm. 31 
المعادلة من أمر ضروري في

الترجمة لأن فيها ضمن مقارنة النصوص المختلفة. ومن أهدافها تقدم المعادلة الدلالية بين لغة المصدر ولغة الهدف. هذا هو ما يفرق أنشطة الترجمة وغيرها، هنا كثير من المشكلة المخفية وكلها ينفذ بمعيار ما يواقع ويقبل من

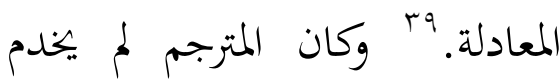
الترجمة مسوية بالنصوص الأصلي. المشكلة الأساسية في عملية

الترجمة بين لغتين هي محاولة إيجاد لفظ ما في لغة ما مطابق للفظ آخر في لغة أخرى. وهذا يفترض من البداية تطابق اللغتين في التصنيف، وفي الخلفيات الثقافة

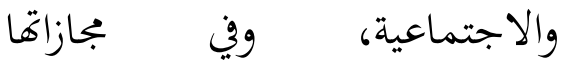
واستخداماتها اللغوية، وفي أخيلتها وتصوراهما. وهو مالا يتحقق ولا يمكن أن يتحقق مطلقا. ويختلف ونفوره اللغويون المحدثون في هذا مع ئرئ أرسطو الذي كان يرى أن المعانى

\footnotetext{
${ }^{39}$ Machali, Pedoman bagi Penerjemah, hlm. 106
}

على المترجم أيضا أن يراعي الى حد كبير الألتزام بجوهر الترجمة، فيما يتعلق بالمعنى واللهجة والأسلوب وغير ذلك ، ونسق النص الأصلي أي شكله من حيث المصادر والمقاطع الكتابية وترك الفراغات اللازمة عند بداية كل مقطع كتابي والأعمدة والجداول وغيرها. ج) العملية التحريرية في شكل عام، تبحي العملية التحريرية بعد فهاية عملية الترجمة. هذه من الأمر مهم فيها. رأى ابن البردة " إذا نفذ المترجم تحرير ذاتي (self-editing) متدارجا من إثناء العملية فقد كانت فعالا. على سبيل المثال، التحرير لايزال في كل باب المترجَم، وبهذا، ذاكرته نحو محتوى النصوص المنقولة لم يزل طزجة حيث العملية أسهل وأركز . برجه

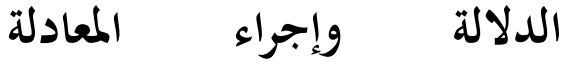 (equivalence)}

\footnotetext{
${ }^{38}$ Ibnu Burdah, Opcit Menjadi Penerjemah:hlm. 36
} 
مناهج البحث

يُستخدم هذا البحث

منهجا من البحث الإرتباطي

(Corelation research)

لأن من البحث الإرتباطي أن يريدَ

الباحث أن يكشف أو يبحث

variasi-) علاقةَ الاختلافات

(variasi

وجود اختلافات من العوامل

الأخرى على أساس المعامل

الإرتباطي (koefisiensi korelasi).

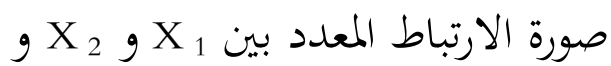

$\mathrm{Y}$

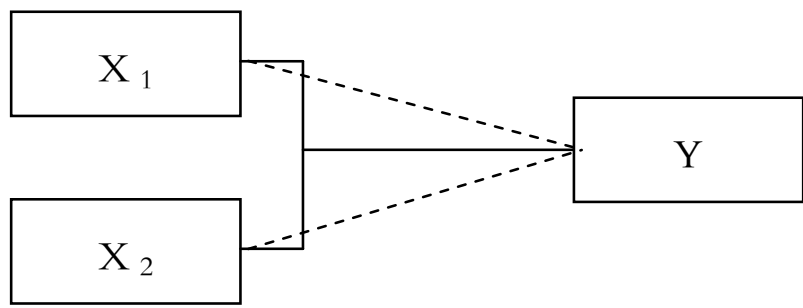

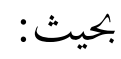

X 1

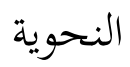

كفاءة المفردات X2

قدرة الترجمة

جتمع البحث هو بميع

أفراد البحث (subjek penelitian).
تتقابل تماما من لغة إلى لغة، بمعنى أن أي كلمة في لغة يمكن أن نجد لما مرادفا مطابقا في اللغة الأخرى. فإذا كان الاختلاف موجودا بين الفرد والفرد من أبناء اللغة، بل بين الفرد ونفسه من موقف إلى موقف، ومن حالة إلى حالة، فإنه موجود ولا شك- بين اللهجة واللهجة، وبين اللغة واللغة. •؛

ومع ذلك، محلة ما يعادل

نص لغة المصدر إلى لغة المدف ليست فيها العلاقة غير الرسمي والأدبي في الترجمة بكيث تصبح قاسية وصعبة للمتحدثين للغة المدف. في هذا السياق، يحتاج على المترجم أن يضع تعريف للترجمة التي تشمل من نظر الرسالة أو معادلة المناسبة، بكعنى أن هناك المترجم يجمع بين حرية للتعبير عن الرسالة ودقة نسبة الترجمة إلى النص

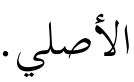

$$
\begin{aligned}
& \text { " أحمد مختار عمر، علم دلالة، (قاهرة: عالم }
\end{aligned}
$$

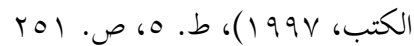


(1) أن يطلب نتيجة عليا بأن

ينظر جدول النيجة المرحلية

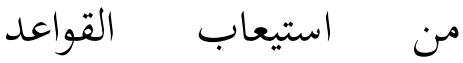

النحوية، ويجد فيه أن النتيجة

$$
\text { العليا هي و v. }
$$

(r) أن يطلب نتيجة سفلى بأن

ينظر جدول النتيجة المرحلية

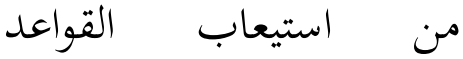

النحوية، ويجد فيه أن النتيجة

$$
\text { السفلى هي ع } 7 .
$$

(ץ) أن يكسب الفترة النوعية

بأن (Interval Katagori)

يقصر النتيجة العليا بالنتيجة

السفلى ويقسمها ثلاثا (من

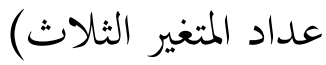

$$
0=\frac{10-V 9}{r}=0
$$

ولذلك، الفترة لنوعية عليا

هي 0، ونوعية وسطى 0،

$$
\text { ونوعية سفلى هي } 0 .
$$

(ع) أن يمدد النتيجة العليا

والوسطى والسفلى بالنوعية

العليا والوسطى و والسفلى
ورأى منذر الضامن، المقصود

بكتمع الدراسة كل العناصر المراد

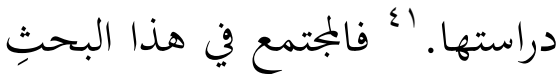

هو جميعُ طلاّب قسم تعليم اللغة

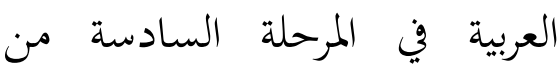

الجامعة الإسلامية الحكومية قدس.

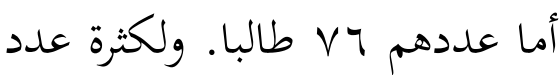

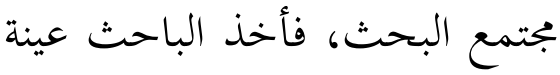

البحث وعددها VV TV

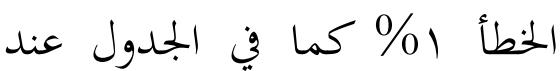

إيساج Isaac وميحيل Michael.

$$
\text { نتائج البحث ومناقشتها }
$$

$$
\text { تحليل البيانات ومناقشتها }
$$

أ) صورة استيعاب القواعد

النحوية لدى طلبة الجامعة

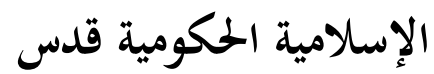

لتحليل البيانات من المتغير الحر

X1

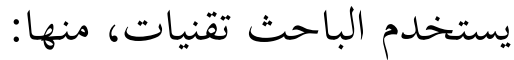

ا" منذر عبد الحميد الضامن، أساسية البحث

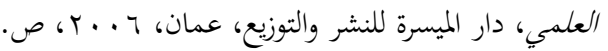


ومن البيانات السابقة لمعرفة

مدى أثر استيعاب القواعد النحوية

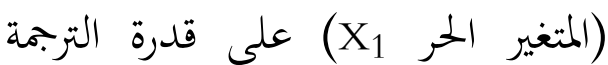

(المتغير المقيد Y) لدى طلبة الجامعة

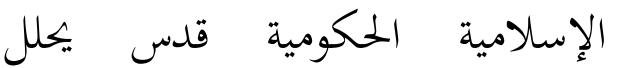

الباحث أولا عن المتغيرين المذكورين

Product moment برمز (Y g $\left.\mathrm{X}_{1}\right)$<smiles>[AsH2][AsH2]</smiles>

اعتمادا عند غاغمن

Gagmen

Vq-V乏 أن أنيجة

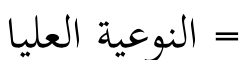

Vr-79

= النوعية الوسطى

ج)

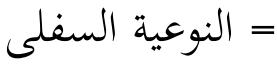

$r x y=\frac{N \sum X Y-\left(\sum X\right)\left(\sum Y\right)}{\left.\sqrt{\left\{N \sum \mathrm{X}^{2}-\left(\sum \mathrm{X}\right)^{2}\right\}\left\{\mathrm{N} \sum \mathrm{Y}^{2}-\left(\sum \mathrm{Y}\right)^{2}\right.}\right\}}$

$r x y=\frac{67 \times 354209-4864 \times 4876}{\left.\sqrt{\left\{67 \times 355724-4876^{2}\right\}\left\{67 \times 353358-4864^{2}\right.}\right\}}$

$r x y=\frac{237732003-23716864}{\sqrt{\{23833508-23775376\}\{23674986-23658496}\}}$

$\mathrm{r} x y=\frac{15139}{\sqrt{\{58132\}\{16490}\}}$

$\mathrm{rxy}=\frac{15139}{\sqrt{958596680}}$

$r \mathrm{xy}=0,4924737$

ولمعرفة قيمة معامل التحديد (koefisien determinasi) بين متغيري X

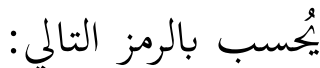

$$
\begin{aligned}
\left(\mathrm{r}_{\text {hitung }}\right)^{2} \times 100 & =(0,4924737)^{2} \times 100 \\
& =0,2425303 \times 100 \\
& =\mathbf{2 4 , 2 5 3 0 3}
\end{aligned}
$$




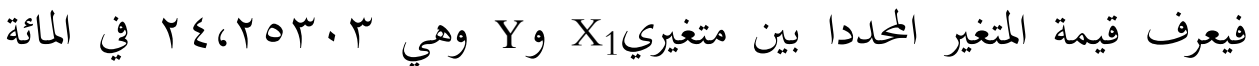

$$
\text { وبقيتها VO, V \& O هي متغير آخر لم تتم دراستها من قبل الباحث. }
$$

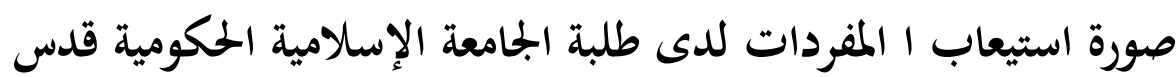

لتحليل البيانات من المتغير الحر X2 (استيعاب المفردات) يستخدم الباحث

$$
\text { تقنيات، منها: }
$$

(1) أن يطلب نتيجة عليا بأن ينظر جدول النتيجة المرحلية من استيعاب المفردات،

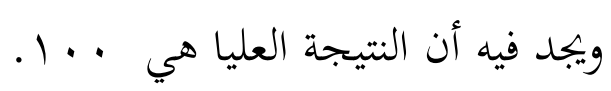

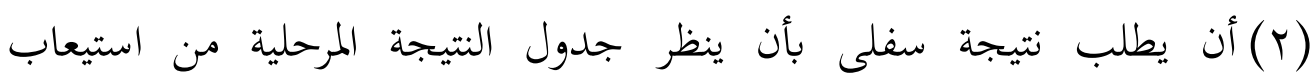

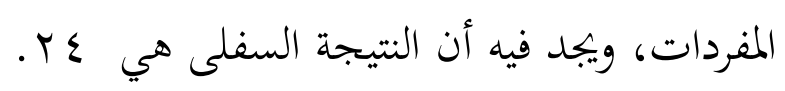

(r) أن يحسب الفترة النوعية (Interval Katagori) بأن يقصر النتيجة العليا بالنتيجة

السفلى ويقسمها ثلاثا (من عداد المتغير الثلاث)

$$
r \circ / r 06 r=\frac{r \varepsilon-1 \cdots}{r}=0
$$

ولذلك، الفترة لنوعية عليا هي OY، ونوعية وسطى OY، ونوعية سفلى هي

(ع) أن يحدد النتيجة العليا والوسطى والسفلى بالنوعية العليا والوسطى والسفلى

اعتمادا عند غاغمن Gagmen كمرجع. كما يلي:

$$
\begin{aligned}
& \text { النتيجة YV- . . 1 = النوعية العليا }
\end{aligned}
$$

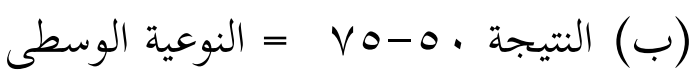

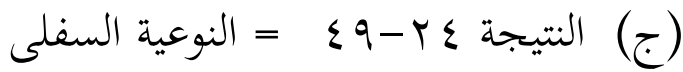


ومن البيانات السابقة لمعرفة مدى أثر كفاءة المفردات (المتغير الحر X2) على قدرة الترجمة (المتغير المقيد Y) لدى طلبة الجامعة الإسلامية الحكومية قدس يحلل

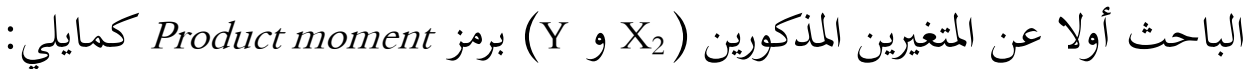

$r x y=\frac{N \sum X Y-\left(\sum X\right)\left(\sum Y\right)}{\left.\sqrt{\left\{N \sum X^{2}-\left(\sum X\right)^{2}\right\}\left\{N \sum Y^{2}-\left(\sum Y\right)^{2}\right.}\right\}}$

$r \mathrm{xy}=\frac{67 \times 377564-5184 \times 4874}{\left.\sqrt{\left\{67 \times 424128-4864^{2}\right\}\left\{67 \times 353358-4864^{2}\right.}\right\}}$

$r x y=\frac{25296788-25214976}{\sqrt{\{28416576-26873856\}\{23674986-23658496}\}}$

$r x y=\frac{81812}{\sqrt{\{1542720\}\{16490\}}}$

$r x y=\frac{81812}{\sqrt{25439452800}}$

$r x y=0,605186$

ولمعرفة قيمة معامل التحديد (koefisien determinasi) بين متغيري X و X، يُحسب

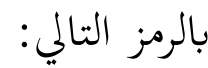

$$
\begin{aligned}
\left(r_{\text {hitung }}\right)^{2} \times 100= & (0,605186)^{2} \times 100 \\
= & 0,36625 \times 100 \\
& =\mathbf{3 6 , 6 2 4 9 9}
\end{aligned}
$$

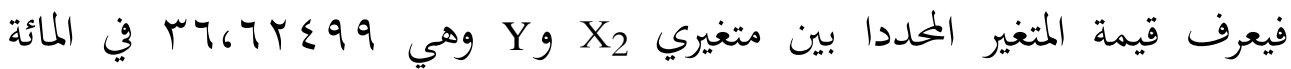
وبقيتها 1 .

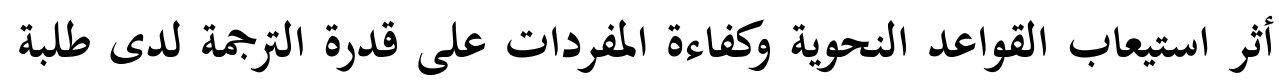

$$
\text { (الجامعة الإسلامية الحكومية قدس الحتبار الفرضية الإحصائية }
$$




$$
\text { (أ) اختبار معامل التحديد (koefisien determinasi) }
$$

(1) معامل التحديد (koefisien determinasi) بين متغيري X و Y X

$$
\begin{aligned}
\mathrm{KD} & =\mathrm{r}^{2}\left(\mathrm{r}_{\text {hitung }}\right) \times 100 \% \\
& =(0,4924737)^{2} \times 100 \\
& =0,2425303 \times 100 \\
& =\mathbf{2 4 , 2 5 3 0 3}
\end{aligned}
$$

(r)

koefisien

، (determinasi

متغيري Y X X

$$
\text { بالرمز التالي: - x }
$$

$$
\mathrm{KD}=\mathrm{r}^{2}\left(\mathrm{r}_{\text {hitung }}\right) \mathrm{x}
$$$$
100 \%
$$

$$
\begin{aligned}
= & (0,605186)^{2} \\
& \times 100 \\
= & 0,36625 \times 100 \\
= & \mathbf{3 6 , 6 2 4 9 9}
\end{aligned}
$$

(ب) اختبار الدلالة المتزامن

\section{Ujian Signifikansi )}

Simultan / Uji Statistik

$$
\text { (F }
$$

هذا الاختبار يدل هل كل المتغير

الحر له أثر متزامن على المتغير المقيد. اختبارF لمعرفة هل متغير X الحرين متزامنا يؤثران دلالة على متغير المقيد. اختبارز $\quad$ Y koefisien ل

determinasi استعملت لتقويم الفرضية.

بنظر اختبار Anova

الجدول r r. السابق يعرف نتيجة احبئ

اختبارF 17.366 أكبر من

، $(\tau \varepsilon=1-Y-T \vee \quad / N-K-1) \quad F_{\text {tabel }}$

هذه تدل على أن المتغير الحر قد استعملت لتقويم الفرضية.

$$
\text { (ج) اختبار Tes }
$$

أصلا، أن اختبار Tes

الإحصائي يدل هل المتغير الحر له

أثثر على المتغير المقيد. لاختبار - Tل "SPSS" الإحصائي يستخدم Tes كأداة الحساب وحاصله كما في الجدول الألي. 


\section{Coefficients $^{\mathrm{a}}$}

\begin{tabular}{|c|c|c|c|c|c|c|c|c|}
\hline \multirow[t]{2}{*}{ Model } & \multicolumn{2}{|c|}{$\begin{array}{c}\text { Unstandardized } \\
\text { Coefficients }\end{array}$} & \multirow{2}{*}{$\begin{array}{c}\text { Standardized } \\
\text { Coefficients } \\
\text { Beta }\end{array}$} & \multirow[b]{2}{*}{ l } & \multirow[b]{2}{*}{ Sig. } & \multicolumn{3}{|c|}{ Correlations } \\
\hline & B & Std. Error & & & & Zero-order & Partial & Part \\
\hline $1 \quad$ (Constant) & 56.848 & 4.022 & & 14.134 & .000 & & & \\
\hline Nahwu & .176 & .059 & .330 & 2.959 & .004 & .489 & .347 & .298 \\
\hline Mufrodat & .038 & .012 & .372 & 3.336 & .001 & .513 & .385 & .336 \\
\hline
\end{tabular}

a. Dependent Variable: Tarjamah

$$
\begin{aligned}
& \text { اعتمادا على هذا الاختبار } \\
& \text { واختتاما في هذا البحث } \\
& \text { يعرف أن قيمة } 2.959 \text { لاستيعاب } \\
& \text { يريد الباحث أن يستنبط أي يأخذ } \\
& \text { القواعد النحوية } \\
& \text { الخالاصة من البحث الذي قد بين } \\
& \text { لا ستيعاب المغردات (X2) . ثم تعدل }
\end{aligned}
$$

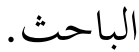

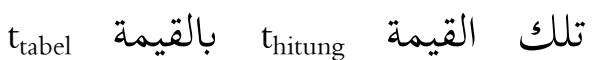

$$
\begin{aligned}
& \text { ا . وجود أثر دلالي من استيعاب } \\
& \text { بوصف اختبار إن كانت القيمة } \\
& \text { القواعد النحوية (X) } \\
& \text { t thitung } \\
& \text { قلرة الترجمة للى طلبة الجامعة } \\
& \text { مقبولة. والعكس، إن كانت القيمة } \\
& \text { الإسلامية الحكومية قدس. أما } \\
& t_{\text {tabel }} t_{\text {hitung }} \\
& 2.959 t_{\text {hitung }} \text { دليله فإن القيمة } \\
& \text { فالفرضية غير مقبولة أو مردود. } \\
& \text { أكثر (X) } \\
& \text { ولذلك، يعرف في هنا البحث أن } \\
& \text { YV 2.66) t tabel } \\
& \text { القيمة } 3.336 \text { و } 2.959 t_{\text {hitung }} \text { (X) } \\
& \text { طلبة وويني درجة الدلالة 0.01). }
\end{aligned}
$$

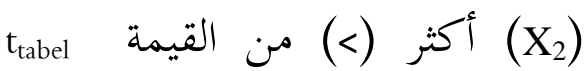

$$
\begin{aligned}
& \text { وهنا ارتباط ايجابي بين } \\
& \text { (2.66 من عداد 7V طلبة ووين درجة } \\
& \text { الدلالة 0.01). } \\
& \text { استيعاب القواعد النحوية } \\
& \text { على قدرة الترجة للى } \\
& \text { طلبة الجامعة الإسلامية }
\end{aligned}
$$


الحلكومية قدس بأن تكون قيمة

(r ne من معامل الارتباط (ritung

ه

الجدول (rabel

على الدلالة أو المقبولة

(signifikan)

المعيار "rabel

koefisien ( معامل التحديد

X بين متغيري (determinasi

و

وبقيتها V0,V

متغير آخر لم تتم دراستها من

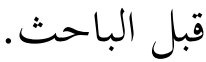

r. وجود أثر دلالي من استيعاب

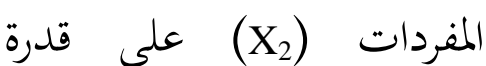

الترجمة لدى طلبة الجامعة

الإسلامية الحكومية قدس. أما

دليله فإن القيمة $3.336 t_{\text {hitung }}$

أكثر (>) من (X)

TV عداد 2.66) $t_{\text {tabel }}$

طلبة وفي درجة الدلالة 0.01).

وهنا ارتباط ايجابي بين

استيعاب المفردات (X) على
قدرة الترجمة لدى طلبة الجامعة

الإسلامية الحكومية قدس بأن

تكون قيمة r من معامل

الارتباط (1, (ritung

أكبر من قيمة الجدول (rabel)

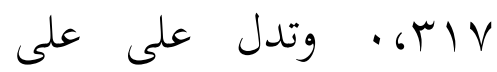

الدلالة أو المقبولة

(signifikan)

المعيار "ritung

المتغير المحددا بين متغيري

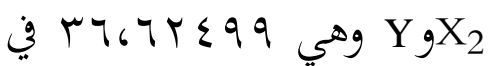

المائة وبقيتها ل.

هي متغير آخر لم تتم دراستها

من قبل الباحث.

r. وجود الارتباط المعدد الدلالي

بين استيعاب القواعد النحوية

والمفردات (X)

قدرة الترجمة لدى طلبة الجامعة

الإسلامية الحكومية قدس بنظر

اختبار Anova يعرف نتيجة

اختبارF 17.366 أكبر من

$-Y-T V / N-K-1) 4,95 F_{\text {tabel }}$

1 
المتغير الحر له الارتباط المعدد

الدلالي وقد استعملت لتقويم

الفرضية والفرضية مقبولة.
(عمان: دار الميسرة، · (Y)؛

r. b

رشدى أحمد طعيمة، المرجع في تعليم

اللغة العربية للناطقين بلغات

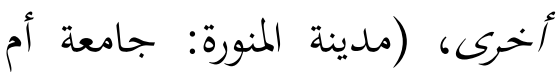

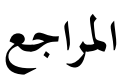

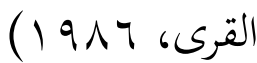

أبو نصر إسماعيل بن حماد الجوهري

سليمان فياض، النحو العصري: دليل

الفارابي، الصحاح تاج العزاج

مبسط لقواعد اللغة العربية،

وصحاح العربية، (بيروت: دار

(القاهرة: مركز الأهرام للترجمة

العلم للملايين، 9NV 1 (1)، ط. 7

والنشر (1990)

أحمد مختار عمر، معجم اللغة العببية

صلاح الدين صالح حسين، دراسة في

المعاصرة، (عالم الكتب، القاهرة،

علم اللغة الوصغي والتاريخي

$(r \cdots \wedge$

والمقارن، (رياض: دار العلوم

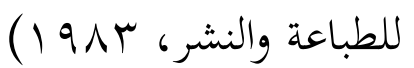

أسعد مظفّر الدين حكيم، علم الترجمة

طه على حسين الديليمي، وسعاد عبد

$(1919$

الكريع عباس الوائلي، اللغة العربية

مناهجها وطرائق تلدربسيها،

(عمان: دار السروق للنشر

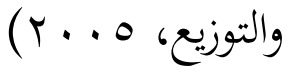

$(1919$

راتب قاسم عاشور، و مُعَّمَ فؤاد الحوامدة،

عباس حسن، النحو الوافي، (مصر: دار المعارف، بدون السنة)، ط. 7، اكن،

أساليب تلدريس اللغة العربية، 
فؤاد نعمة، ملخص قواعل اللغة النحوبة ،

(بيروت: دار الثقافة الإسلامية،

بدون السنة)، ط. 9 الترو

مُحَّْ حسين مغالسة، النحو الشافي،

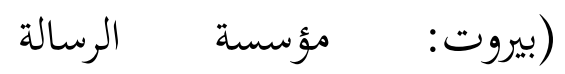

Y). ص. (199V

تُعََّّ مكرم، لسان العرب، (مصر: دار

6 الصادر، بدون السنة)، جل،

محمود كامل الناقة، تعليم اللغة العربية

بلغات آخرى: أسسه - ملداخله

- طرق تلدريس، (مكة المكرمة:

جامعة أم القرى، (910 ( )

مصطفى غلاييني، جامع الدروس

العربية، (بيروت: الملكتبة العصرية،

6) 1. . (199\% 6
منذر عبد الحميد الضامن، أساسية

البحث العلمي، (عمان: دار

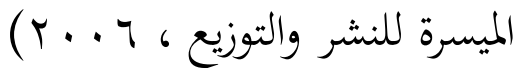

Abdul Munip, Strategi dan Kiat Menerjamah Teks Bahasa Arab kedalam Bahasa Indonesia, (Yogyakarta: Teras, 2009)

Ahmad Fuad Effendy, Metodologi Pengajaran Bahasa Arab, (Malang: Misyka, 2012), cet. 5

Ibnu Burdah, Menjadi Penerjemah: Metode dan Wawasan Menerjemah Teks Bahasa Arab, (Yogyakarta: Tiara Wacana, 2004.)

Ibnu Burdah, Menjadi Penerjemah: Metode dan Wawasan Menerjemah Teks Bahasa Arab, (Yogyakarta: Tiara Wacana, 2004.)

Zuchridin Suryawinata \& Sugeng Heriyanto,Translation: Bahasa Teori \& Penuntun Praktis Menerjemahkan, (Yogyakarta: Kanisius, 2003) 